\title{
Retraction
}

\section{Retracted: A Fatal Case of Wernicke's Encephalopathy after Sleeve Gastrectomy for Morbid Obesity}

\author{
Case Reports in Surgery \\ Received 23 March 2016; Accepted 23 February 2017; Published 15 March 2017 \\ Copyright ( 2017 Case Reports in Surgery. This is an open access article distributed under the Creative Commons Attribution \\ License, which permits unrestricted use, distribution, and reproduction in any medium, provided the original work is properly \\ cited.
}

\begin{abstract}
At the request of the authors, the article titled "A Fatal Case of Wernicke's Encephalopathy after Sleeve Gastrectomy for Morbid Obesity" [1] has been retracted. The coroner reviewed the case and postmortem histopathology and concluded that the typical histopathological lesions of Wernicke's encephalopathy were absent, therefore not confirming the initial diagnosis. Reexamination of the patient's file showed that postoperative vitamin B1 levels were within the institutional reference range; no hyperemesis and no neurological signs were revealed. The article stated that "This report is published with the written consent of the patient's family," but there was misunderstanding and the family did not give explicit permission for publication.
\end{abstract}

\section{References}

[1] D. K. Manatakis and N. Georgopoulos, "A fatal case of Wernicke's encephalopathy after sleeve gastrectomy for morbid obesity," Case Reports in Surgery, vol. 2014, Article ID 281210, 4 pages, 2014. 


\title{
A Fatal Case of Wernicke's Encephalopathy after Sleeve Gastrectomy for Morbid Obesity
}

\author{
Dimitrios K. Manatakis and Nikolaos Georgopoulos \\ 2nd Surgical Department, Athens Naval and Veterans Hospital, 70 Deinokratous Street, Athens, Greece
}

Correspondence should be addressed to Dimitrios K. Manatakis; dmanatak@yahoo.gr

Received 2 July 2014; Accepted 26 August 2014; Published 7 September 2014

Academic Editor: Kevin Reavis

Copyright (C) 2014 D. K. Manatakis and N. Georgopoulos. This is an open access article distributed under the Creative Commons Attribution License, which permits unrestricted use, distribution, and reproduction in any medium, provided the original work is properly cited.

At the request of the authors, this article has been retracted. The coroner reviewed the case and postmortem histopathology and concluded that the typical histopathological lesions of Wernicke's encephalopathy were absent, therefore not confirming the initial diagnosis. Reexamination of the patient's file showed that postoperative vitamin B1 levels were within the institutional reference range; no hyperemesis and no neurological signs were revealed. The article stated that "This report is published with the written consent of the patient's family," but there was misunderstanding and the family did not give explicit permission for publication.

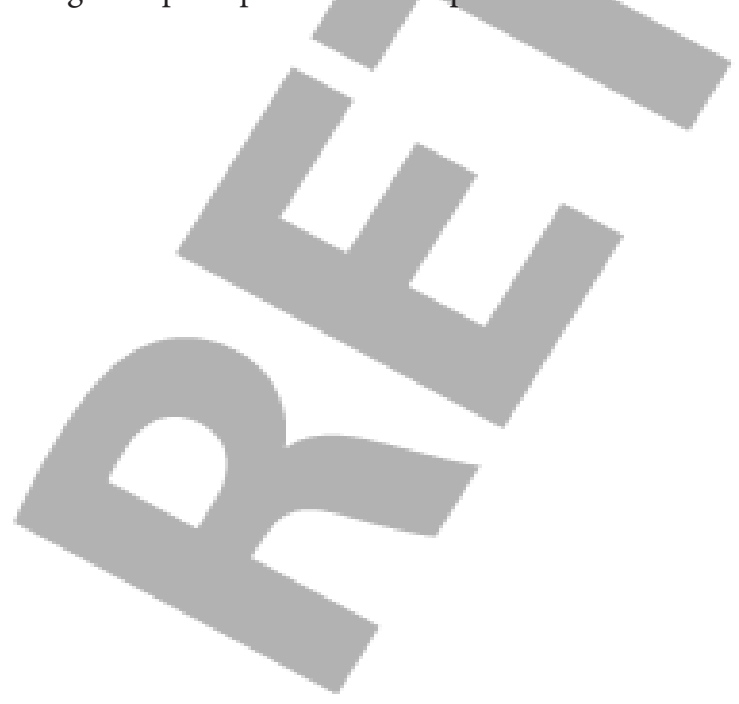



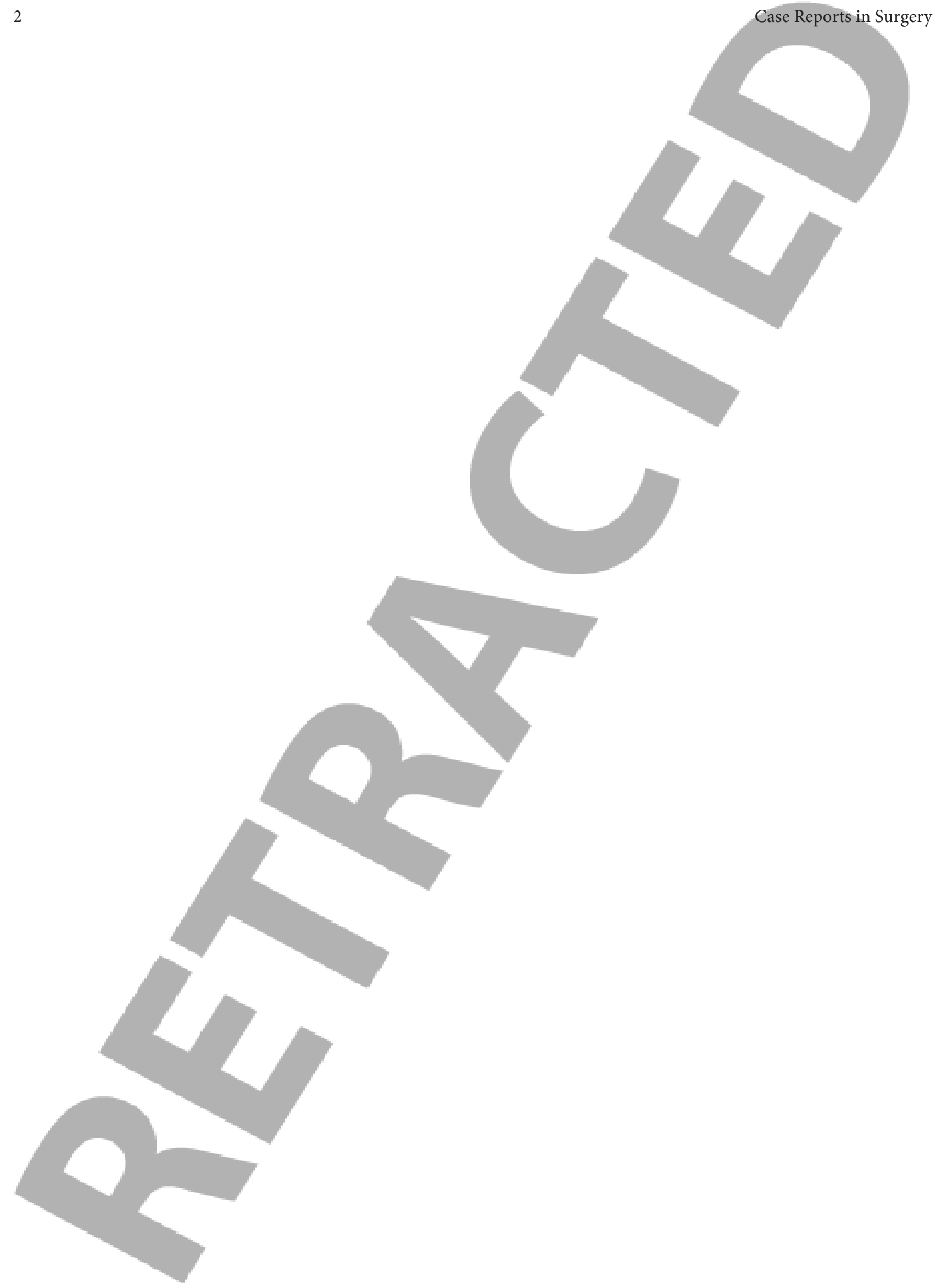

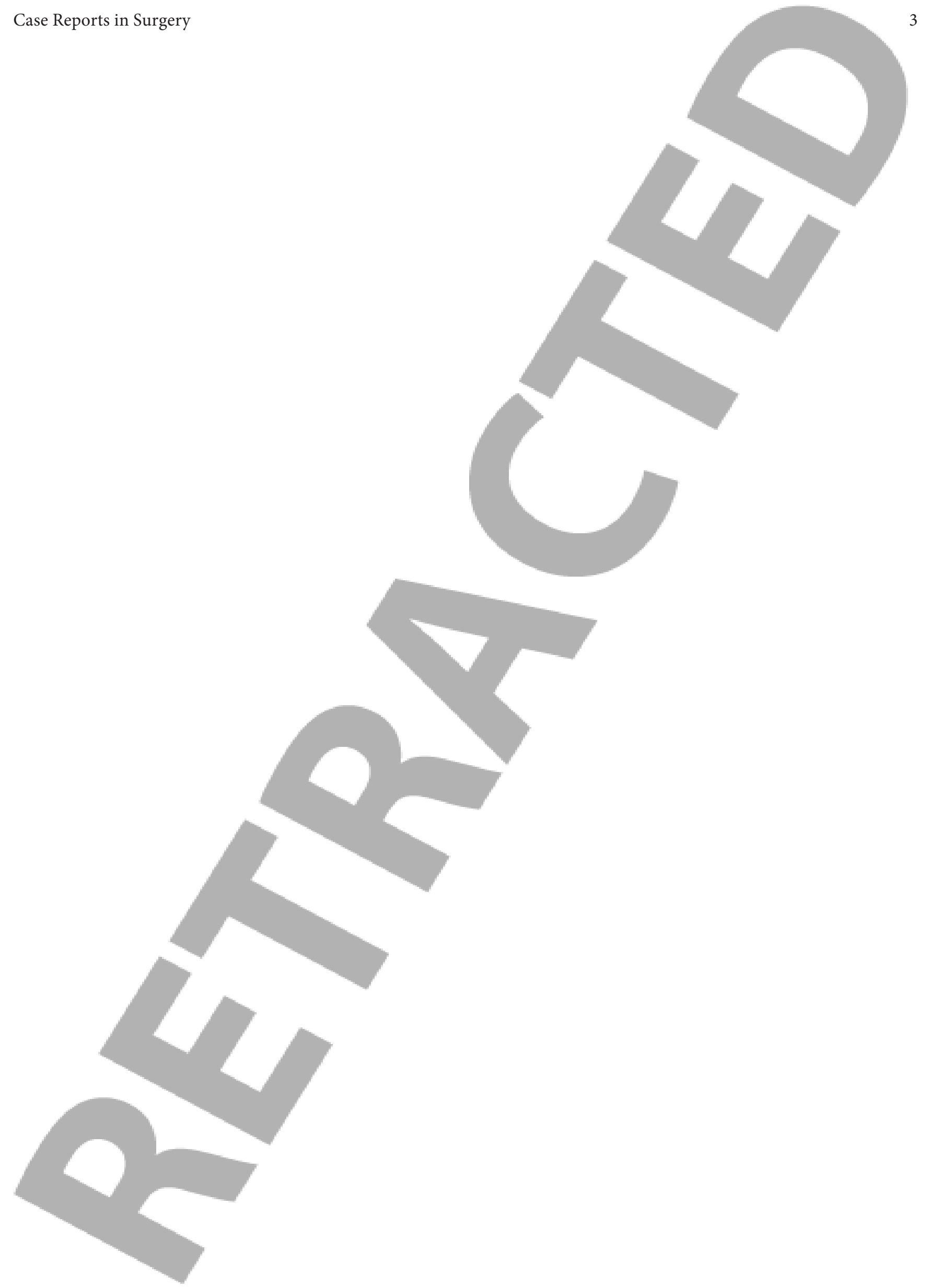

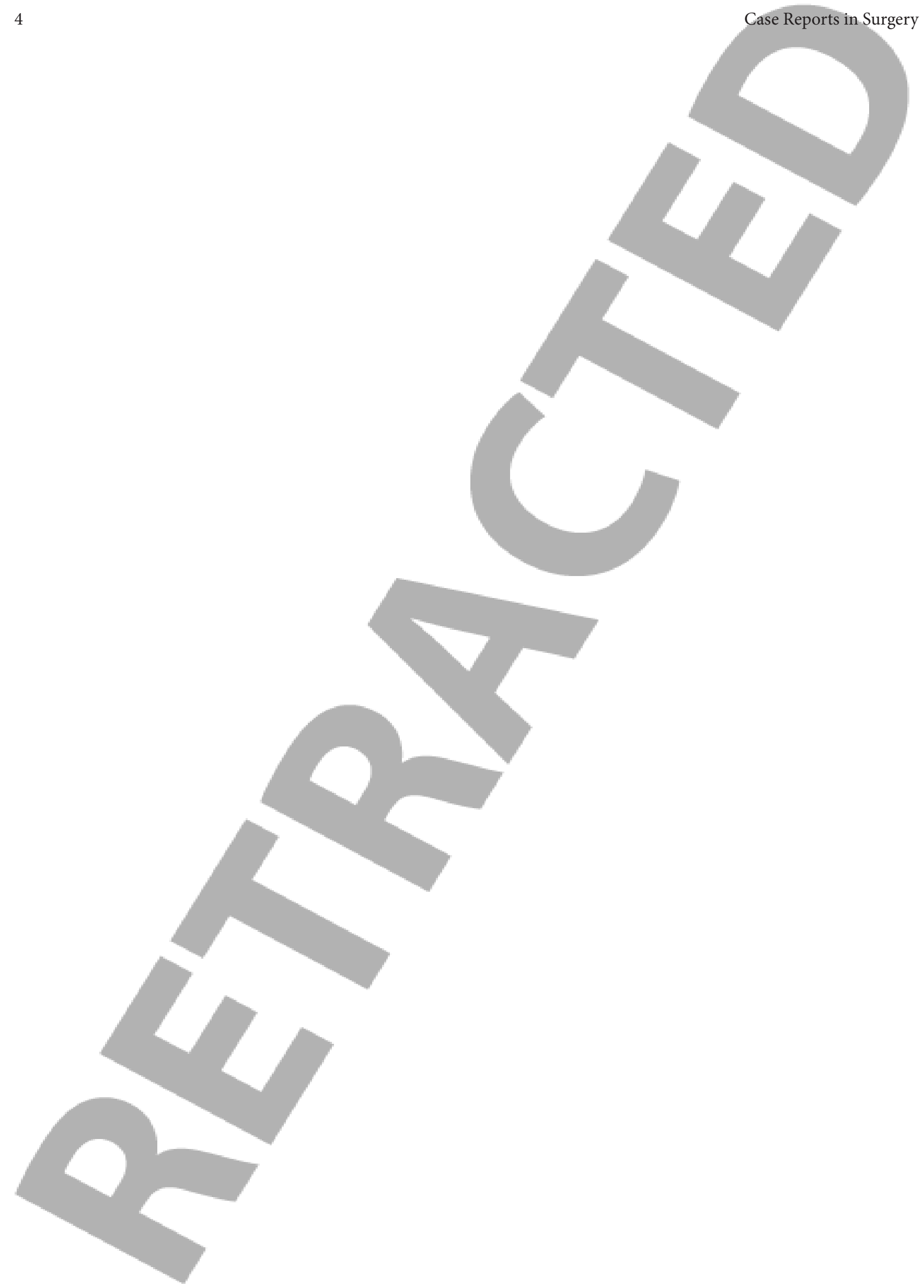